\title{
Through German:
}

\section{Contemporary Literature in Translation}

The voices of so many countries echo through the selection of contemporary literature here: Germany, Austria, and Switzerland, but also Turkey, Moldova, England, Syria, Ghana, Romania, Ukraine, and Israel. Images of a movement that is never free recur: passports, border patrols, wars, sadness, awkward encounters, words that do not quite fit. While this issue of Absinthe has a distinct international flair, it is not, however, a selection of Migrantenliteratur, a category that fences in writers as foreign rather than German or Austrian or Swiss, that pretends that some are always at home and some belong only with an asterisk. Rather, the voices we have translated into English here are all integral to the German-speaking world and its representation, whether the authors were born there, arrived decades ago, or came recently to perhaps find another home, perhaps pass through.

All of the authors are alive, but that may be the only thing they have in common. Not even all of the texts here were originally written in German: Abdullah Alqaseer's gutting story, "A Lie Named Germany," was written in Arabic before Mustafa Al-Slaiman translated it into German; Serhiy Zhadan's poems, translated into German by Claudia Dathe, originally appeared in Ukrainian. You will have heard of some of the authors; the names of others will likely be unfamiliar. Taken together, we believe that they give a fuller version of what it means to live in the Germanosphere in the twenty-first century, at a time when many Americans in particular still associate Central Europe with ethnically homogenous countries and its literature predominantly with white men.

All texts were chosen, translated, and collaboratively edited by a group of graduate students in the Departments of Comparative Literature, English, and Germanic Languages and Literatures at the University of Michigan: Lauren Beck, Elisabeth Fertig, Ivan Parra Garcia, Lena Grimm, Özlem Karuç, Michaela Kotziers, Elizabeth 
Sokol, and Veronica Cook Williamson. Silke-Maria Weineck served as the faculty advisor and editor-in-chief.

We have decided to call this issue "Through German," a title that stresses the language as medium, passage, barrier, portal, or sieve. Translation itself is a common theme: translating your name or your identity, translating your cat, translating yourself into an older or a younger version of yourself, translating your identity, your childhood, your history, or seeing language merge with the natural world where meaning dissolves into materiality. It is only fitting, then, that the issue closes with a reflection on the very process of translation that the last text in this volume, Elfriede Jelinek's "Ballad of Three Important Men and Also of the Circle of Persons Around Them." 